\title{
A Monographic Study of Mathematical Thinking in the Field of Early Education from the Perspective of Subject Quality
}

\author{
Erjing Zhang
}

\begin{abstract}
This paper analyzes the current circumstances of the mathematical thinking training industry in the field of preschool education in China under the supply-demand theoretical framework in the first place. On the demand side, the author summarizes how elements such as policy guidance, upgraded distribution of public consumption, upgraded parents' attitudes toward children's education drive the thriving period of mathematical thinking. On the supply side, this paper finds through statistics that after ten years of development, now mathematical thinking training institutions in the market can be divided into online and offline institutions, traditional tycoons and emerging enterprises. In addition, the author discusses the present teaching system of mathematical thinking training in China and makes a summary from two aspects --- teaching mode and curriculum setting. Last, based on the analyses above, this paper identifies the future trends of this area in terms of technological convergence and regional distribution.
\end{abstract}

Index Terms-Mathematical thinking, preschool education, quality-oriented education, subject education.

\section{INTRODUCTION}

Kant once said that the purpose of education for children should be uniting knowing with doing to help them better prepare for future challenges. Among all the subjects, mathematics appears to be the subject that best satisfies this requirement. Furthermore, it is mathematical thinking that exceeds beyond the concept of subject and is closely linked with advanced cognitive functions of an individual like logical thinking and creating. In a highly informationalized society, the abovementioned abilities are all highlighted, and its development trajectory with the growth of an individual has been extensively studied in recent years. Research conducted by the Center on the Developing Child at Harvard University shows that children enter a critical period for developing logical thinking and judgement after age one, and the development reaches a peak at four to five-year-old [1]. Furthermore, as pressure from entrance examination gradually shifts forward and is transmitted downward, an increasing number of Chinese parents begin to pay serious attention to the cultivation of mathematical thinking for their preschool children.

Following children's cognitive logic of concrete-abstractconcrete, mathematical thinking emphasizes pondering and solving a problem in a mathematical way, with an aim to lead children not to purely memorize knowledge and improve their abilities to observe, analyze, judge, create and operate [2] The current mathematical thinking training in China mainly targets preschool children, and it aims at developing critical thinking through gamified and interactive teaching and dealing with problems arising from the transition for kindergarten to primary school. Different from traditional mathematics training which focuses on doing exercise for exams, mathematical thinking training combines subject education with quality-oriented education with a younger target audience and easier courses, and its contents are more closely linked with real-life scenarios [3].

As a positive response to the burden alleviation policy enacted by the administrative department and the special governance of "prohibiting primary school-oriented nursery education," mathematical thinking-related products receive a significant amount of capital support [4]. Based on the supply-demand theoretical framework, the author concludes that mathematical thinking will become another big incremental preschool education market after English and programming training for children. However, most of existing literature advocate that a teacher should treat mathematical thinking training as a focus of teaching for the purpose of improving teaching method, but there is little systematic and comprehensive analysis on the whole current situation and future trends of mathematical thinking in academia. Thus, this paper conducts a multi-dimensional and in-depth analysis of the evolutionary logic behind mathematical thinking, summarizes its achievements in the current stage, and further analyzes its sustainability and trends, in order to offer advice and suggestions for educators and people from all walks of life.

\section{ANALYSIS OF MATHEMATICAL THINKING INDUSTRY'S DEMAND}

\section{A. Regulatory Policies on Subject Tutoring Emerge \\ Frequently and Bring New Opportunities to Mathematical Thinking}

Since 2018, education regulatory policies have been issued frequently: extracurricular training regulation has continued to upgrade, and these policies focus on easing extracurricular burden for primary and secondary school students and advocating quality-oriented education. In the field of subject training, after-school training institutions are prohibited from organizing any K12 contest, from linking correlating 
outcomes with enrollment, and from making any promise about admission and examination. In the realm of qualityoriented training, trainings which aim at developing K12related hobbies, spirit of innovation and practical skills are encouraged by governments.

Meanwhile, with the all-round reform of the transition from kindergarten to primary school, subject-oriented mathematical products are gradually shifted toward qualityoriented. Under the strict rectification of over-instruction, exam-oriented education, etc., tests and competitions represented by "Mathematical Olympiad" are called off, so parents do not need to cram knowledge into their children. The boost from these policies brings about new opportunities to mathematical thinking based on quality-oriented development of subject-based mathematics [5].

\section{B. Improvement of Economic Living Standard Lays a Foundation for the Popularity of Preschool Education}

As shown in Fig. 1, in China, per capita disposable income has grown for successive years, with an average compound annual growth rate of $9.04 \%$ from 2013 to 2018, and per capita disposable income was around 28,200 CNY in 2018. Compared with the residents' consumption expenditure, which has been decreasing year after year, the consumption expenditure on education, culture and entertainment has a reverse trend of consistently increasing, reflects the families' rising attention and willingness to pay for children's education and the fact that preschool education industry is well under way owing to rapid economic growth of the country.

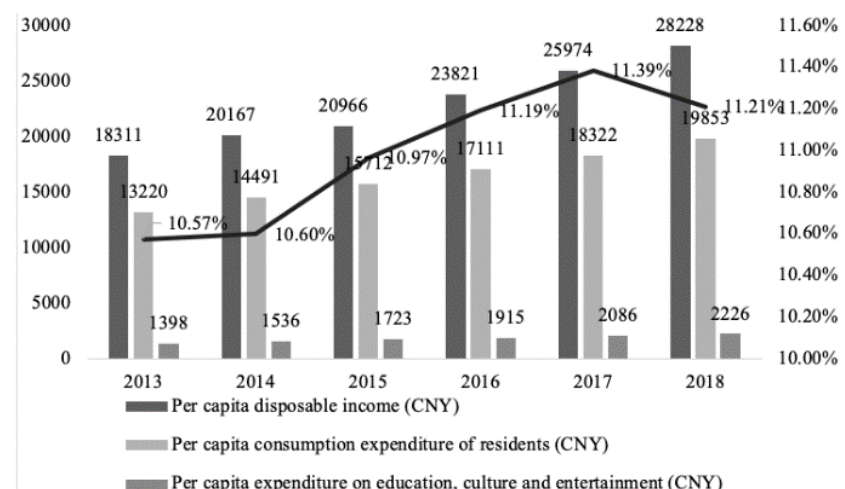

Fig. 1. Per capita disposable income and expenditure of Chinese residents from 2013 to 2018.

Data source: National Bureau of Statistics.

\section{Upgrading Consumption: Changing View of Educational Consumption}

The variance in the age composition of consumers leads to the differing view of educational consumption, and the penetration rate of mathematical thinking has considerable space for development. The new generation of students' parents are mostly post-80s and -90 s, and compared with post-60s and -70s, the former's focus on children's education start to switch from "rigid demand" of test-oriented education to long-term returns of quality-oriented training. Beneficiaries and decision-makers are different in preschool education, so it is necessary to understand parents' concerns about their children's study and needs in different stages at first. Preschoolers' parents need a holistic education solution, and course contents in mathematical thinking, language course for beginners and STEAM are interdependent, which can help children develop comprehensively [6]. After children enter elementary schools, different subjects have their independent system of knowledge with weak connections between each other, so their parents will selectively let their children to take supplementary lessons for the subject in which the children have poor performances.

With the expansion of the middle class, parents are more willing to invest in education, especially quality-oriented education training for children. As shown in Fig. 2, household expenditure on child-rearing is positively correlated with household income in China: nearly $90 \%$ of parents would spend $20 \%$ of their annual income on child-rearing-related expenditures; with the constant growth of the household income, household expenditure on child-rearing has ranged from 20,000-50,000 CNY to 50,000-300,000 CNY. Future increase in Chinese family income will unleash the market potential of the parenting field simultaneously.

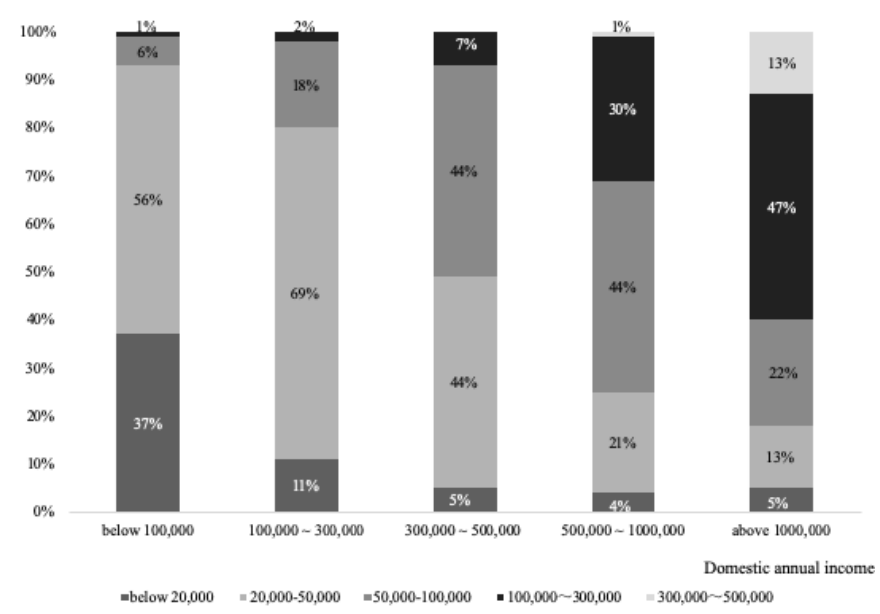

Fig. 2. Composition of different family income levels and different levels of childrearing expenditure.

Data source: 2018 Weibo Report on the Trends of Family Consumption in Education for Children.

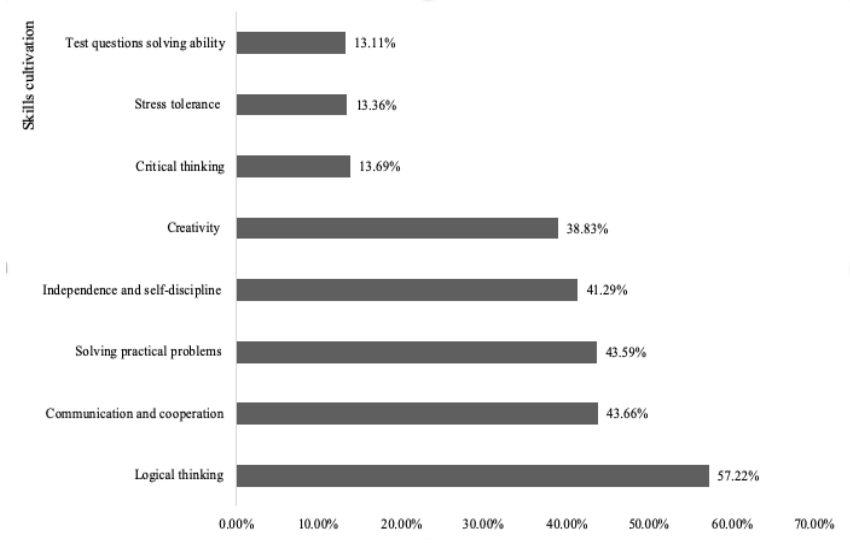

Fig. 3. Parents value training children's logical thinking ability the most. Data source: 2018 Survey Report on Burden Alleviation for Primary/Secondary School Students.

\section{Logical Thinking Ability Draws Much Attention}

According to 2018 Survey Report on Burden Alleviation for Primary and Secondary School Students, Fig. 3 demonstrates that parents have apparent expectations on fostering children's abilities in all aspects and they value logical thinking ability the most. The question solving abilities that traditional test-oriented education attaches 
importance to takes up only $13.11 \%$, which indicates that parents' emphasis on children's learning ability has become more scientific and diversified. The upgrading educational consumption prompts traditional test-oriented education to gradually turn to quality-oriented education, as students trained by traditional test-oriented education overstress scores, while quality-oriented education promotes all-around development. Mathematical thinking training combines subject education and quality-oriented education, cultivating children to achieve not only great academic performances but also social competence.

\section{ANALYSIS OF MATHEMATICAL THINKING INDUSTRY'S SUPPLY}

\section{A. Technology + Education Empowers Training Institutions of Mathematical Thinking}

Aiming at meeting the requirements of elementary school entrance examination, children's mathematical thinking training started from offline institutions, which mainly concentrated in east China, typically in Shanghai where has the most developed private schools. Previously, restricted by the supply of excellent teachers and parents' awareness, the industry expanded slowly with low market coverage. As of now, since online live streaming technology has been proven and online English training for children has expanded the market, the educational model of online live streaming is completely accepted by public. When children's mathematical thinking combines with an online model, there is no need for companies to spend a long time inspecting and selecting a site and deal with government relations, as online classroom is ready-to-use as needed, and reaches all the customers nationwide. By embracing the megatrend of putting everything online, the mathematical thinking training industry experiences explosive growth.

\section{B. Online and Offline Players Contend for the Huge Mathematical Thinking Market}

In the field of mathematical thinking, a batch of new companies emerge, and traditional leading K12 companies and offline education tycoons also start setting up marketing plans. Offline mathematical thinking training is mainly divided into two kinds: one kind is the brands subordinate to traditional K12 training institutions, who set up offline mathematical thinking training earlier, e.g. TAL Mobby and OneSmart Happymath. Another kind is regional offline institutions, e.g. Smartbrook and Whizkids. Online mathematical thinking training is also divided into two types: one type is emerging online education companies who have created mathematical thinking brands for children in recent years, e.g. Zhangmenkid and Luna-ed of VIPKID. Another type is institutions which focus on online mathematical thinking and are established later, e.g. Huohua and VIPThink.

\section{ANALYSis of Mathetical Thinking TEACHING SYSTEM}

\section{A. Teaching Mode}

\section{1) Small-class teaching with lowering students' ages}

Most target customers of mathematical thinking training are children aged three to twelve. Compared with traditional Mathematical Olympiad courses which focus on keeping doing difficult and tricky problems, mathematical thinking training relies on scientific methods to cultivate logical thinking with lowering students' ages [7]. In terms of class type, different from online English class which mostly adopts 1V1 model, mathematical thinking features one-to-many small class. First, online English class needs to give every student time to express verbally, while in a mathematical thinking class, students can think simultaneously to ensure class efficiency. Second, the thinking curriculum design incorporates peer coaching and needs to ensure the number of people. The math class mostly adopts "three fixed" model, namely "fixed teaching hours, teachers and peers," which can lower the adaption cost, ensure the coherence of study, enable a peer learning environment, allow students to help each other, and create an inspiring atmosphere [8].

\section{2) Gamification and interactive teaching}

The greatest innovation of mathematics thinking course lies in its improvement of teaching methods, as they generally incorporate game and animation into the teaching process with the use of teaching aids. The training integrates internationally advanced teaching concepts (Table I) into the teaching model, employing gamified and situational teaching methods to instill pleasure into study. Mathematical thinking training aligns concepts, such as STEAM and traceable teaching methods, with Chinese actual situations, and arouses students' interest in learning and consolidate their knowledge through guidance and reciprocal interactions. It can also intuitively display abstract contents like spatial stereographs to boost children's spatial imagination [9].

TABLE I: INTEGRATION OF INTERNATIONALLY ADVANCED TEACHING CONCEPTS

\begin{tabular}{|l|l|}
\hline Company & Teaching method \\
\hline Happymath & $\begin{array}{l}\text { Incorporate the Case Method of Harvard University } \\
\text { into basic education, propose the concept of learning } \\
\text { capacity, and stress active learning and interactive team } \\
\text { teaching by establishing a multi-dimensional } \\
\text { interactive teaching system }\end{array}$ \\
\hline Zhangmen & $\begin{array}{l}\text { Take the pyramid of thinking development as its } \\
\text { teaching philosophy, consult NCTM curriculum } \\
\text { Standards, use Jean Piaget's constructivist theory and } \\
\text { Inquiry-based learning (IBL) }\end{array}$ \\
\hline VIPThink & $\begin{array}{l}\text { Immersive animated classroom based on NCTM } \\
\text { evaluation criteria and achievements of frontline } \\
\text { teachers in China }\end{array}$ \\
\hline
\end{tabular}

Data sources: official websites of these companies

An immersive learning environment created through situationalization and gamification can optimize the interactive experience of online mathematical thinking course. Situationalization is for enhancing students' concentration in class. The greatest challenge for online education is to create a favorable learning environment which can allow learners to immerse themselves in it. By adding animation elements to class, learning knowledge in an animated situation truly enables children to play while studying and study while using While gamification means making learning more interesting. The biggest difference between learning and gaming is that learning stresses delayed satisfaction, while in games students may get prompt rewards through quantitative growth of the attributes of game characters, and this is the root reason why 
game players are highly self-motivated [10]. If we can use digital technology and internet to gamify the learning process and enable students to get instant rewards in each stage of study, it will address students' autonomy issue to a great degree.

\section{B. Curriculum Design}

\section{1) Progressive curriculum system creates a scientific learning loop}

Mathematical thinking course is set according to thinking patterns of children of different age groups, and its curriculum system is progressive. Since preschool children are in the stage of enlightenment, we should focus on developing their sound learning habits and interests and helping them find pleasure in learning mathematics form daily life and, therefore, succeed in the transition from kindergarten to elementary school.

Professional entrance examination + situational interactive animated teaching + homework + tracking \& assessment constitute a scientific loop for learning [11]. Through entrance examination, it helps children orient accurately, provides a basis for making an individualized learning plan after starting school, and matches corresponding courses and peers according to assessment results. Besides, situational interactive animated teaching is used to motivate children to learn. Moreover, homework can reinforce what is learned in class, and tracking \& assessment can formulate an effective feedback mechanism according to the performance of children in each learning stage and monitor learning outcomes at any time to facilitate their developmental progress [12].

2) Periodic evaluation feedback visually presents teaching results

The essence of education is the superposition of logical attachment and affective attachment, which means it not only needs to increase affective attachment between teacher and student, but also needs a more perceivable outcome, namely logical attachment. Compared with perceivable learning outcomes yielded by English training for children, a challenge for mathematical thinking training course is that its learning outcomes are hard to explicitly present [13]. From the parents' perspectives, the course cannot be limited to playing games and telling stories, as they hope to see the practical outcomes in a given period of time. To resolve this challenge, related companies start with course development and after-class tracking and assessment. For example, Happymath will set aside 10-15 minutes before class ends to interact and communicate with parents, and it will use full digital and intelligent measurement techniques and man-machine conversation to perform accurate measurement and staged tracking of children's mathematical thinking ability, to present parents objective, authentic, scientific and reliable developments of their children's mathematical ability.

\section{ANALysis OF Future TRENDS OF THE MATHEMATICAL THINKING TRAINING INDUSTRY}

\section{A. A New Round of Technological Revolution Empowers Mathematical Thinking}

With technological means like AI, future mathematical thinking training will further enrich its course content, improve the form of teaching and increase classroom efficiency. Technological empowerment is roughly divided into two ways: replace and assist. The use of AI technology can give AI teacher the ability to observe and understand children's operation and release AI-empowered mathematical thinking course. The use of AI big data monitoring can intelligently generate a mind map and record the growth track of children via AI, to make knowledge check more pertinent and assist in classroom teaching [14]. In 2019, VIPThink planned to set up AI Smart Classroom, which replaces some functions of a teacher with $\mathrm{AI}$ and continues to empower education with technology.

The deep integration between AI and education may provide precise education which teaches students according to their aptitude with data support and suggestion, achieve stratified teaching in accordance with the learning process of different students, and make individualized learning plans [15]. Based on powerful curriculum system and original courseware, AI teacher can offer targeted interactive classroom experience coupled with abundant immediate feedback and stimuli. Besides, VR/AR technologies can enhance the immersiveness of online education. Energetically creating AI-empowered mathematical thinking course is for using technological means to reproduce real teaching scenarios most faithfully and planning and guiding for students to learn in a more scientific and pertinent way. In addition, technology allows children to allocate learning time flexibly and freely and do exercise repeatedly at anytime and anywhere, which reduces learning-related time cost and economic cost for both parents and children while reinforcing learning outcomes.

\section{B. Mathematical Thinking is Extended to Lower-Tier Markets}

In 2016, China initiated a comprehensive two-child policy, then the population of newborns keeps increasing, so the markets of mathematical thinking training in cities in developed regions are expected to continue to expand. At present, China's mathematical thinking training market matures gradually in first-tier cities, such as Beijing, Shanghai, Guangzhou and Shenzhen, and second-tier cities like provincial capitals, while it still in the stage of development and has great development potential in thirdand fourth-tier cities. As economic level increases and education awareness is enhanced, third- and fourth-tier cities and rural citizens will also usher in the revolution of educational concept. Mathematical thinking will put effort into lower-tier markets, convey high-quality courses to thirdand fourth-tier cities, achieve the sharing of high-quality educational resources, and promote equity in education.

In addition, in the case of the outbreak of COVID-19 at present, Chinese offline training institutions are hit hard, as most of small- and medium-sized institutions are confronted with capital chain rupture, but they may put all of their courses online to further increase the penetration rate of online teaching, mathematical thinking training is no exception. The popularization of online education is greatly expedited because of the epidemic. Online education is intrinsically characterized by irrespectiveness of time and place, and this special period of time facilitates the rapid 
expansion of mathematical thinking training in lower-tier cities.

\section{CONCLUSION}

Mathematical thinking education is a kind of training which takes mathematics as the main carrier and focuses on improving logical thinking. It concentrates on the critical age bracket of preschool when children form their thinking, and it is conducted with quality-oriented education model. It offers educational contents that develop mathematical cognition, logical thinking, judgement, analysis and other abilities. In view of the cognition level and personality traits of young children, now mathematical thinking course basically takes game and animation as its primary form of presentation in terms of content, with an aim to attract children's attention and arouse their interest in learning. In the future, mathematical thinking will use AI technology to fragment knowledge points and teaching, and employ AI algorithm and deep learning to quickly adjust the content of courses accordingly, thus achieving the effective communication of course contents.

On the whole, after the comprehensive and in-depth analysis, the author draws the conclusion that mathematical thinking will be a very promising direction for early education, and its core logic is that its attributes of both subject education and quality-oriented education make its training more extendable acceptable. Moreover, compared with general quality-oriented education, it has more rigid demand, and it accords with contemporary educational philosophy and parents' requirements for abilities more than general subject education. At last, as AI and VR technologies are deeply integrated with education scenarios, mathematical thinking will achieve stratified teaching and individualized teaching objectives more effectively; besides, as education is extended to lower-tier areas, mathematical thinking will also bring whole new teaching experience to more children in lower-tier cities in China.

Due to the limitations of references and the length of paper, this paper concentrates on analyzing the market of mathematical thinking training for preschool children in China, yet cultural and economic differences will make different regions differ in their demand for mathematical thinking and opinions on reasonable teaching systems. The author is tremendously interested in preschool education and will continue to discuss in this direction in depth.

\section{CONFLICT OF INTEREST}

The author declares no conflict of interest.

\section{AUTHOR CONTRIBUTIONS}

The author Erjing Zhang conducted the research, analyzed the data, and wrote the paper. She hopes to offer special thanks to Ms. Yichen Wang, who gave considerable guidance and support for this research.

\section{REFERENCES}

[1] S. Dehaene, "Sources of mathematical thinking: Behavioral and brainimaging evidence," Science, vol. 284, no. 5416, pp. 970-974, 1999.

[2] T. Dreyfus, "Advanced mathematical thinking," Mathematical Thinking \& Learning, vol. 7, no. 1, pp. 15-25, 2005.

[3] N. Cengiz, K. Kline, and T. J. Grant, "Extending students' mathematical thinking during whole-group discussions," Journal of Mathematics Teacher Education, no. 14, 2011.

[4] J. Cai, "Assessing and understanding U.S. and Chinese students' mathematical thinking," Zentralblatt Für Didaktik Der Mathematik, vol. 34, no. 6, pp. 278-290, 2002.

[5] J. L. Fraivillig, L. A. Murphy, and K. C. Fuson, "Advancing children's mathematical thinking in everyday mathematics classrooms," Journal for Research in Mathematics Education, vol. 30, no. 2, p. 148, 1999.

[6] A. Hachey, "The early childhood mathematics education revolution," Early Education \& Development, vol. 24, no. 4, p. 419, 2013.

[7] L. Erlbaums, Mathematical Thinking and Learning, 2006

[8] M. Y. Leung, Promoting and Measuring Mathematical Thinking and Strategy Use in Young Children through Computer-Based Activities, 2008.

[9] M. Karwowski, D. M. Jankowska, and W. Szwajkowski, "Creativity, imagination, and early mathematics education," Creativity and Giftedness, 2017.

[10] M. Edo, N. Planas, and E. Badillo, "Mathematical learning in a context of play," European Early Childhood Education Research Journal, vol. 17, no. 3, pp. 325-341, 2009.

[11] F. A. Adam, Play, Interaction, and Early Mathematics, 2010.

[12] E. F. Dijk, B. Oers, and J. Terwel, "Schematising in early childhood mathematics education: Why, when and how?" European Early Childhood Education Research Journal, vol. 12, no. 1, p. 71, 2004.

[13] A. Testolin, "The challenge of modeling the acquisition of mathematical concepts," Frontiers in Human Neuroscience, p. 1, 2020.

[14] T. D. Jules and F. D. Salajan, The Educational Intelligent Economy: Big Data, Artificial Intelligence, Machine Learning and the Internet of Things in Education, Emerald Publishing Limited, 2019.

[15] D. H. Clements and J. Sarama, "Math, science, and technology in the early grades," Future of Children, vol. 26, no. 2, pp. 75-94, 2016.

Copyright $@ 2020$ by the authors. This is an open access article distributed under the Creative Commons Attribution License which permits unrestricted use, distribution, and reproduction in any medium, provided the original work is properly cited (CC BY 4.0).

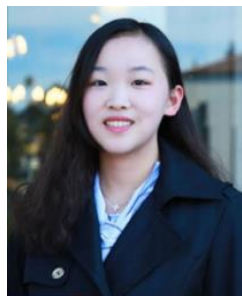

Erjing Zhang was born in China in 1999 and is now attending University of California, Berkeley as an undergraduate student who major in psychology and minor in education. Her research interest lays in developmental psychology, specifically about language acquisition, linguistic conventionality, and the link between infant walking and early vocabulary acquisition. 